\title{
OS PRIMEIROS QUATRO MESES DA COBERTURA DA PANDEMIA DA COVID-19 NO JORNAL NACIONAL
}

\author{
Paulo Eduardo Silva Lins CAJAZEIRA ${ }^{1}$ \\ José Jullian Gomes de SOUZA ${ }^{2}$ \\ Cleide Luciane ANTONIUTTI ${ }^{3}$ \\ Universidade Federal do Cariri | Brasil
}

\begin{abstract}
Resumo
Este artigo objetiva compreender os processos jornalísticos da cobertura da pandemia da Covid-19 pelo Jornal Nacional da TV Globo, de 18 janeiro a 15 de maio de 2020. Considera-se que desde o surgimento da doença, e suas consequências, as atenções dos jornalistas foram divididas em três crises políticas geradas pelo governo federal: 1) a demissão do ex-ministro da Saúde Luiz Henrique Mandetta; 2) o pedido de demissão do ex-ministro Sérgio Moro do Ministério da Justiça e Segurança Pública; e 3) o pedido de demissão do ex-ministro da Saúde Nelson Teich.

Monotematização; Cobertura jornalística; Covid-19; Jornal Nacional.

Abstract

This article aims to understand the journalistic processes of coverage of the Covid-19 pandemic by Jornal Nacional from TV Globo from 18 January to 15 May 2020. It states that since the onset of the disease and its related consequences, the focus of attention of journalists was divided between three political crises generated by the Brazilian federal government: 1) the dismissal of former Health Minister Luiz Henrique Mandetta; 2) the resignation of ex-minister Sergio Moro of the Ministry of Justice and Public Security and 3) the resignation of former Health Minister Nelson Teich.
\end{abstract}

\section{Keywords}

Monothematic process; News coverage; Covid-19; Jornal Nacional TV news program.

\section{RECEBIDO EM 14 DE SETEMBRO DE 2020} ACEITO EM 8 DE JULHO DE 2021

\footnotetext{
${ }^{1}$ Professor Associado da Universidade Federal de Pelotas - UFPel. Doutor em Comunicação e Semiótica - PUCSP Contato: paulo.cajazeira@ufpel.edu.br.

2 Pesquisador do Centro de Estudos e Pesquisa em Jornalismo - Universidade Federal do Cariri - UFCA. Mestre em Biblioteconomia pela UFCA. Contato: jullianjose64@gmail.com.

${ }^{3}$ Professora Adjunta da Universidade Federal do Cariri. Doutora em Ciência da Informação - IBICT/UFRJ. Contato: luciane.antoniutti@ufca.edu.br
} 


\section{Introdução}

este estudo buscou-se investigar os quatro primeiros meses de
cobertura jornalística em da Covida-19 em televisão, e os efeitos
produzidos nas narrativas do Jornal Nacional da TV Globo. Com o crescimento da Covid-19 no Brasil e no mundo no primeiro semestre de 2020, a cobertura jornalística transformou-se em monotemática preocupada com aspectos sociais, econômicos, políticos e os índices de audiência, conforme o estudo mostrará ao longo da Investigação. Deste modo, identificamos que no período enfocado para este estudo, a cobertura jornalística do Jornal Nacional da TV Globo vai sendo constituída e apresentando picos de edições diárias que discorrem apenas sobre a Covid-19 - como será possível observar no momento da análise do objeto de estudo.

Este artigo se propõe a analisar e discutir alguns aspectos da cobertura televisiva do Jornal Nacional (JN) sobre a Covid-19 no que tange aos processos de monotematização e as influências de temas políticos na cobertura da pandemia. A nossa análise de conteúdo começa em 18 de janeiro e se estende até o dia 15 de maio de 2020, considerado o período de exibição da primeira reportagem, as primeiras vítimas, o aumento no número de casos da doença e a disseminação global resultando na decisão da Organização Mundial da Saúde (OMS) em decretar pandemia do novo coronavírus chamado de SarsCov-2.

Junto a isso, no Brasil, a crise política se instala e o tema da crise sanitária divide-se com a crise política, a partir da saída do governo do Presidente Jair Bolsonaro (sem partido) de três ministros de Estado: Luiz Henrique Mandetta (Saúde), Sérgio Moro (Justiça e Segurança Pública) e Nelson Teich (Saúde). Desde o início da crise sanitária, o presidente brasileiro Jair Bolsonaro tem contrariado as recomendações da OMS e estado presente em diferentes atos públicos, saudando pessoas, sem nenhuma proteção 


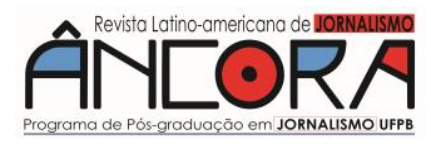

\title{
Paulo CAJAZEIRA - José SOUZA - Cleide ANTONIUTTI
}

(máscara ou distanciamento) e minimizando os riscos e efeitos nocivos do novo coronavírus.

Procurou-se, também, fazer um breve comparativo da cobertura jornalística com alguns temas de saúde: o surgimento da Aids (1983 a 1987); a pandemia da Gripe H1N1 (2009) e a microcefalia (2015). A relação da pandemia e a imprensa tem se mostrado monopolizadora, próxima e constante, conforme afirma o Boaventura de Souza Santos (2020, p. 37-38) sobre o novo coronavírus:

\begin{abstract}
Sabe cómo monopolizar la atención de los medios como el mejor experto en comunicación social. Descubrió nuestros hábitos y la proximidad social en la que vivimos para afectarnos más duramente. El coronavirus es nuestro contemporáneo en el sentido más profundo del término. No es solo porque es simultáneo, es decir, que ocurre en el mismo tiempo lineal que nuestras vidas.
\end{abstract}

Começamos o nosso estudo refletindo a respeito das relações do novo coronavírus e a contemporaneidade a partir das palavras do pesquisador português, Boaventura Santos, no artigo "El coronavírus y nuestra contemporaneidade", recém-publicado no livro Alerta Global: políticas, movimientos sociales y futuros em disputa en tiempos de pandemia. No período de análise da cobertura, as demais temáticas e assuntos não foram cobertas pelo telejornal, havendo apenas abordagens e ângulos acerca dos temas que perpassam a cobertura da Covid-19. Isso se configura como um momento único na cobertura jornalística do Jornal Nacional da TV Globo, que completou 51 anos em 01 de setembro de 2020, e a televisão brasileira os seus 70 anos em 18 de setembro de 2020.

\section{História da atuação da mídia nas recentes crises sanitárias no Brasil}

A primeira cobertura jornalística no JN com caráter monotemático sobre saúde ocorreu na década de 1980, a partir do surgimento da Aids (1983 a 1987). As primeiras reportagens discorreram sobre a descoberta do vírus e o 
crescimento da então denominada "epidemia mais violenta do século", conforme informações da primeira reportagem sobre o tema "Primeiras informações ao público brasileiro sobre a Aids" realizada em 27 de março de 1983 pelo Fantástico e, durante a semana, pelo JN, conforme explicita o site Memória Globo.

É preciso considerar que os arquivos de notícias não estão todos disponíveis, tornando complexa a categorização, precisamente sobre a quantidade e datas das abordagens dessa cobertura jornalística monotemática. Porém, o site Memória Globo informa que em $1^{\circ}$ de junho de 1987 foi descoberto um novo tipo do vírus - o terceiro tipo - sendo uma cobertura realizada pelo Jornal Nacional diretamente de Washington, capital dos EUA, de onde se acompanhava a reunião com 6 mil especialistas de 50 países, que discutiam sobre o tema.

O segundo período de cobertura monotemática do JN teve como protagonista a pandemia de Gripe H1N1 (2009). O surto da Influenza A/H1N1 transformou-se na primeira pandemia do século XXI e matou mais de 2 mil pessoas no País, como destaca o site Memória Globo ao rememorar esta cobertura jornalística realizada pelo JN. Na segunda cobertura monotemática sobre saúde, identificamos algumas datas e as temáticas abarcadas por essa cobertura jornalística.

No dia 24 de abril de 2009, o telejornal destacou que o vírus da gripe H1N1 estava chegando ao território dos EUA, depois de matar 20 pessoas no México, sendo esta a primeira notícia sobre a doença, citada no Brasil. Já no dia seguinte, 25 de abril, uma nova reportagem anunciava que o Ministério da Saúde criou um gabinete para lidar com casos da gripe H1N1. Notamos, diferentemente do que ocorreu com a cobertura da Covid-19, que o início dessa cobertura apresentou um número menor de reportagens dedicadas ao tema, semelhante à atual cobertura da Covid-19.

João Pessoa - Brasil | ANO 8 VOL.8 N.1 | JAN./JUN. 2021 | p. 172 a 191 


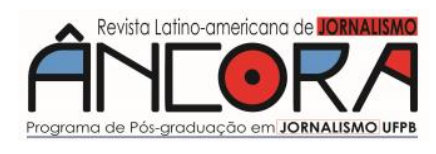

Paulo CAJAZEIRA - José SOUZA - Cleide ANTONIUTTI

Em seguida, o telejornal destacou uma notícia, em 27 de abril, acerca da chegada de duas pessoas no Brasil que vieram do México e que estavam internadas em Belo Horizonte, sob suspeita de terem contraído o vírus. Em São Paulo, outra pessoa apresentava sintomas, cujo resultado ainda não era confirmado.

Desse modo, no mês de abril de 2009, identificamos três notícias que exibiam o surgimento da doença, as ações do governo e a chegada da doença no Brasil. Uma nova reportagem foi visualizada no mês de maio de 2009, discorrendo sobre o número de casos confirmados, com a participação de um homem que teria sido o primeiro infectado com a doença no Rio de Janeiro. Esta foi a única notícia encontrada sobre o tema neste mês, disponível no site Memória Globo. Por último, observamos uma reportagem do JN, em 11 de junho, na qual a correspondente Sônia Bridi, de Paris, mostrou o que os governos da Europa estavam fazendo como resposta ao alerta da doença.

Um terceiro momento monotemático na cobertura jornalística do JN, ocorreu no ano de 2015, cujo tema era a microcefalia. Para discorrermos sobre essa cobertura, faz-se preciso destacar que ela ocorre ao mesmo tempo em que se constata a existência de uma epidemia de dengue no Brasil, noticiada pelo telejornal em 14 de maio de 2015. Em seguida, no dia 22 de maio, o JN noticiou que a cidade de São Paulo registrava o primeiro caso de Zika vírus. Já em 22 de julho, a cobertura destacava os criadouros de Aedes Aegypti (inseto transmissor da dengue e o Zika vírus) em obras que deveriam ter sido entregues para a Copa do Mundo do Brasil em 2014.

Neste primeiro momento, visualizamos que o número de reportagens sobre o tema consta em pequena escala, ao menos diante da análise do material disponível para consulta. Essas três primeiras reportagens ocorrem com um espaçamento de tempo, especialmente entre 22 de maio e 22 de julho (cerca de dois meses de diferença) e as suas temáticas têm abordagens distintas. Dessa forma, é possível fazer uma relação direta com a cobertura da 
microcefalia (uma malformação congênita, em que o cérebro não se desenvolve de maneira adequada) que, como confirmou o Ministério da Saúde, manteve aproximação com o Zika vírus.

Assim, em 6 de outubro, o JN anunciou o registro de 700 mortes por dengue em todo o Brasil. Em 11 de novembro destacava o estado de emergência na saúde pública e a explosão de casos de microcefalia em Pernambuco, que registrava 141 casos em 44 municípios. Já em 21 de novembro de 2015, a reportagem teve uma abordagem política e explicava que os ministérios brasileiros se uniram para conter os casos de microcefalia na região Nordeste. Posteriormente, em 27 de novembro, a reportagem noticiou a primeira morte por Zika vírus no Brasil. E, no dia seguinte, 28, o JN noticiou que o Ministério da Saúde havia confirmado a relação entre a microcefalia e o Zika vírus em bebês.

No mês de dezembro, no dia 8, o telejornal destacou o aumento de $41 \%$ de casos de microcefalia no Brasil. O Ministério da Saúde investigava 19 casos suspeitos da doença e da relação com o Zika vírus. Diante do exposto, compreendemos que esses três momentos que antecedem a atual cobertura sobre o tema saúde foi realizada em conjunto com a cobertura de outras notícias sobre o País e o mundo, havendo espaços temporais no telejornal quando comparada ao novo momento de monotematização com a cobertura da Covid-19, que tem como característica a intensificação massiva em torno de um mesmo tema, não havendo espaço para cobrir outras notícias que estão acontecendo.

\section{Revisão teórica}

Estudar o telejornalismo brasileiro neste momento da pandemia da Covid-19 demanda sobretudo uma reflexão quanto ao papel que a mídia exerce para a formação de uma sociedade mais crítica, com cidadãos mais bem informados e conscientes sobre as problemáticas relacionadas à temática 


\section{ÂNEORA}

Paulo CAJAZEIRA - José SOUZA - Cleide ANTONIUTTI

da doença, que atinge hoje, de forma igualitária, a população mundial. As informações ocorrem tanto ao nível do internacional para o nacional, já que os casos tiveram início na China, e do nacional para o local, uma vez que os casos de Covid-19 foram introduzidos nas grandes capitais, via aeroportos com voos internacionais adentrando as cidades interioranas.

Dessa forma, cabe aqui entender para quem os âncoras e repórteres dos telejornais se dirigem ao estruturar o noticiário, o que creem que seja mais ou menos relevante, e o que entendem que pode ou não interessar aos espectadores. Assim, o que eles julgam que deve ser exibido em seus telejornais, é o que ainda buscaremos entender a partir da análise que empreendemos durante a cobertura jornalística feita pelo Jornal Nacional, da Rede Globo.

Uma informação, desde a sua seleção até a sua publicação, independentemente do meio de comunicação, atravessa etapas, que vão desde a interpretação dos critérios de noticiabilidade por parte dos profissionais do veículo, passando pelas etapas de seleção das fontes, coleta dos dados, produção, até a interpretação desses mesmos critérios pelo editor antes da apresentação final ao público.

Para compreensão de todos esses processos, buscamos aporte teórico nas teorias do jornalismo, especificamente no agendamento da mídia, ou a hipótese da agenda-setting, $e$ nas teorias do gatekeeper e newsmaking (WOLF, 2005 TRAQUINA, 2004 2005; 2008; TUCHMAN, 1978), que defendem que o jornalismo está longe de ser o espelho do real. "E, antes, a construção de uma suposta realidade" (PENA, 2008 p. 128), ou seja, a produção da notícia, embora possa parecer um processo simples, precisa ser planejada como uma rotina industrial.

A hipótese da agenda-setting parte do pressuposto de que os meios de comunicação de massa possuem certa capacidade em determinar as pautas públicas, a partir daquilo que veiculam (McCOMBS; SHAW, 1972). Dearing e 
Rogers (1996) definem uma agenda como um conjunto de temas que comunicam, de acordo com uma hierarquia de importância, em um determinado momento no tempo- Um tema na agenda, por sua vez, é definido como "um problema social, conflitivo, que recebeu atenção dos media" (DEARING; ROGERS, 1996, p. 3). Tais definições têm servido de base para a construção de desenhos de pesquisa destinados a mensurar efeitos de transferência de relevância de uma agenda a outra, em todas as fases das pesquisas em agenda-setting.

McCombs (2005) afirma que até uma breve menção no telejornal da noite é capaz de evidenciar a relevância de um acontecimento, e a localização da notícia no programa e o tempo de duração fornecem pistas da valoração de certos fatos em relação a outros. Assim, a agenda da mídia, de fato, passa a se constituir também na agenda social. O processo de agenda-setting, por sua vez, é composto pelo funcionamento e pelas relações observáveis entre a agenda dos media, a agenda pública e a agenda política (DEARING; ROGERS, 1996), cujas naturezas se dão em termos de definições operacionais.

Entende-se que mais do que sinalizar fatos em destaque, as informações selecionadas diariamente pelos profissionais da mídia, "dirigem nossa atenção e influenciam em nossa percepção de quais são os temas mais importantes do dia. A capacidade para influenciar na relevância das questões do repertório público é o que se chamou de fixação da agenda por parte dos meios informativos" (MCCOMBS, 2006, p. 24). Assim, de uma forma mais simples, poderíamos dizer que os meios de comunicação ordenam os temas de relevância (agenda dos meios de comunicação). A partir daí, é que o público que acompanha, monta sua própria agenda - a agenda pública, que vai se relacionar com seu repertório de assuntos e de ações -, constituindo, assim, 0 nível inicial da opinião pública.

Uma grande contribuição para as teorias do jornalismo foi também o estudo de White, em 1950. Ele nos ajuda a compreender todo o processo da 


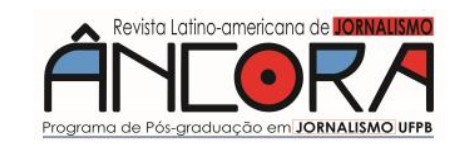

Paulo CAJAZEIRA - José SOUZA - Cleide ANTONIUTTI

seleção de notícias, apresentando as principais razões para publicar e para rejeitar uma notícia. Da mesma forma, Wolf (2005) apresenta estudo que contribui para compreendermos como se dão os critérios usados para o processo de seleção e construção da notícia nos meios de comunicação. Cabe aqui relembrar o que são essas teorias e como devem ser inseridas em nosso trabalho de pesquisa, a partir da cobertura do JN sobre a Covid-19.

Kurt Lewin, psicólogo alemão, em 1947, foi o primeiro autor com preocupações sociais na área da comunicação de massas a indicar que a passagem de uma notícia por determinados canais de comunicação depende de "portões" (gates) que funcionam dentro desses mesmos canais de comunicação 4 (CORREIA, 2011). Esses portões "são regidos ou por regras imparciais ou por um grupo no 'poder', os quais têm o papel de decisão que tem o papel de decisão: o que aprovar e o que rejeitar. O termo gatekeeper acaba por ser aplicado, assim, "à pessoa que toma uma decisão numa sequência de decisões" (TRAQUINA, 2004, p. 77).

A teoria do newsmaking é considerada uma atualização e complementação da teoria do gatekeeper, que busca compreender os critérios de noticiabilidade, pois procura entender todo o processo de rotina de produção da notícia, isto é, os critérios que levaram a notícia a ser veiculada. Em seus estudos Mário Erbolato e Mauro Wolf falam de três momentos: captação, redação, edição (ERBOLATO, 2006); e coleta, seleção, apresentação (WOLF, 2005). Já Mike Ward (2006) defende que o processo jornalístico deve ser descrito em quatro momentos: identificar, obter, selecionar, ordenar ou apresentar.

\footnotetext{
${ }^{4}$ A teoria do Gatekeeper surgiu pela primeira vez no ano de 1947, criado pelo psicólogo alemão Kurt Lewin, a partir de suas observações que levantam a possibilidade da mudança de hábitos alimentares de uma população. Lewin presumiu que nem todo membro de uma comunidade dispõe de igual prestígio para escolher entre quais alimentos vão ou não para a mesa, ao perceber que nos canais por onde escorrem a sequência de comportamentos, certas regiões podem funcionar como cancelas ou porteiros restringindo ou não a passagem dos itens alimentícios (CORREIA, 2011).
} 
O que difere os dois autores, Wolf e Erbolato, de Ward, é que este acrescenta o "identificar" em seus processos. A explicação está no fato de que os que defendem apenas três etapas o fazem, possivelmente, porque a fase de identificação não pode ser percebida por aqueles que fazem a análise a partir do produto final. Somente por quem estiver acompanhando, de dentro da redação, o processo de construção da notícia. Cabe entender então que: "[...] as análises sobre o newsmaking descrevem o trabalho de comunicação dos emissores como um processo que 'contém de tudo'"' (WOLF, 2005, p. 267).

Assim, a partir dessas teorias é possível entender de que forma os telejornais, em específico o Jornal Nacional (JN), da Rede Globo, empreenderam na escolha de critérios de noticiabilidade, a partir das suas rotinas de produção da notícia, na cobertura do Covid 19.

\section{Procedimentos metodológicos}

A metodologia adotada para o presente estudo tem natureza aplicada e perpassa a abordagem quantiqualitativa, objetivando tanto a análise numérica quanto as causas e motivações do fenômeno pesquisado. De acordo com Minayo e Sanches (1993, p. 247) "[...] é de se desejar que as relações sociais possam ser analisadas em seus aspectos mais 'ecológicos' e 'concretos' e aprofundadas em seus significados mais essenciais". Diante do entrelaçamento destas abordagens, poderemos identificar e explicar o processo de monotematização na cobertura jornalística do Jornal Nacional acerca da Covid-19.

Enquanto estratégia de investigação, foi utilizada a pesquisa exploratória-descritiva com a finalidade de compreender a relação entre jornalismo e saúde, referente às coberturas jornalísticas monotemáticas no histórico JN. Para Richardson (2011), este modelo de pesquisa tem como objetivo a familiarização com o tema e a descrição sistemática do fenômeno de modo objetivo e detalhado. Também foram utilizadas a pesquisa 


\section{ANIEORA}

\section{Paulo CAJAZEIRA - José SOUZA - Cleide ANTONIUTTI}

bibliográfica sobre a monotematização e as coberturas jornalísticas sobre saúde e pandemias.

A análise dos dados obtidos ocorreu através do uso da Análise de Conteúdo (AC). De acordo com Bardin (2016), a AC funciona tanto como um método de pesquisa, quanto uma técnica de análise. Conforme uso da AC enquanto técnica de análise, a autora destaca a importância da criação de categorias, que na presente pesquisa se caracterizam a partir das reportagens que versavam sobre a temática da Covid-19. Para essa categorização, as reportagens foram selecionadas segundo o uso das palavras-chave (pandemia, Covid-19 e novo coronavírus) identificadas no título das reportagens ou no texto de apresentação. Posteriormente, as reportagens foram organizadas por mês (entre janeiro e maio de 2020), para que fosse possível identificar como a monotematização se apresentada durante a cobertura do JN.

$E$, acerca da atual cobertura jornalística na TV, vem demonstrando aspectos e mudanças interessantes que necessitam de uma investigação em caráter científico, enquanto forma de corroborar para a compreensão deste cenário jornalístico. O período de análise foi delimitado de 18 de janeiro a 15 de maio de 2020, diante da identificação da primeira notícia sobre o surgimento do coronavírus na China e, em seguida, do avanço do coronavírus pelo mundo e sua chegada ao Brasil. O corpus de análise é composto por reportagens do JN com a temática da Covid-19, que foram coletadas no aplicativo Globoplay, totalizando 909 reportagens no período de análise. Também utilizamos o site Memória Globo, para coletar informações sobre a linha do tempo, a partir da datificação de coberturas de saúde no JN. Assim, os dados analisados foram tabulados e apresentados graficamente, para uma melhor visualização e compreensão acerca da monotematização.

\section{Análise da cobertura jornalística do Jornal Nacional}


Nesta perspectiva, tratando especificamente da atual cobertura jornalística monotemática da Covid-19 realizada pelo Jornal Nacional, notamos um aumento significativo nos meses de março e abril, frente ao período de análise, quando foi iniciado o distanciamento e isolamento social no Brasil. Sobre a temática da Covid-19, os números de reportagens quase quintuplicaram no mês de março (322), em comparação ao mês de fevereiro (70), como pode ser visualizado na tabela a seguir:

Tabela 1 - Quantidade de reportagens sobre a Covid-19 no Jornal Nacional

\begin{tabular}{|c|c|}
\hline Mês & $\begin{array}{c}\mathbf{N}^{\circ} \text { de } \\
\text { reportagens }\end{array}$ \\
\hline Janeiro & 23 \\
\hline Fevereiro & 70 \\
\hline Março & 322 \\
\hline Abril & 331 \\
\hline Maio & 165 \\
\hline
\end{tabular}

Fonte: Elaboração própria (2020)

Assim, constatamos que a temática da pandemia atual, no ano de 2020, exerceu certa predominância nas reportagens do JN. Anteriormente, o telejornal compreendia uma ampla gama de temas tais como saúde, educação, política, cotidiano, esportes e acontecimentos na vida das celebridades. Contudo, conforme a referida pandemia chegava ao mundo ocidental, especialmente às Américas, houve a mudança de uma politematização para uma monotematização.

Conforme a Tabela 1 evidencia, houve um aumento de mais de $300 \%$ entre o primeiro e o segundo mês de análise. Já entre fevereiro a abril, visualizamos um aumento que foi de quase $500 \%$ em relação ao período inicial. Para efeitos de análise, encara-se que no mês de abril houve o ápice da monotematização do telejornal, ou seja, encara-se o fenômeno de forma 


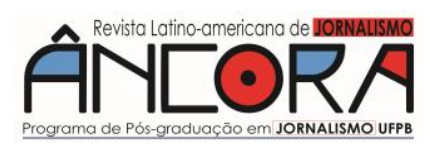

\section{Paulo CAJAZEIRA - José SOUZA - Cleide ANTONIUTTI}

segmentada, e não de forma absoluta e indivisível. De fato, trata-se de um momento de uma cobertura monotemática - como já visualizado em outros momentos, mas de forma mais acentuada -, precedido e seguido de uma forte predominância da temática da Covid-19 nas reportagens do Jornal Nacional.

No mês de abril a monotematização das notícias continuou em crescimento, totalizando 331 reportagens, como mostra o Gráfico 1, a seguir.

Gráfico 1 - Crescimento da monotematização da cobertura noticiosa do Jornal Nacional

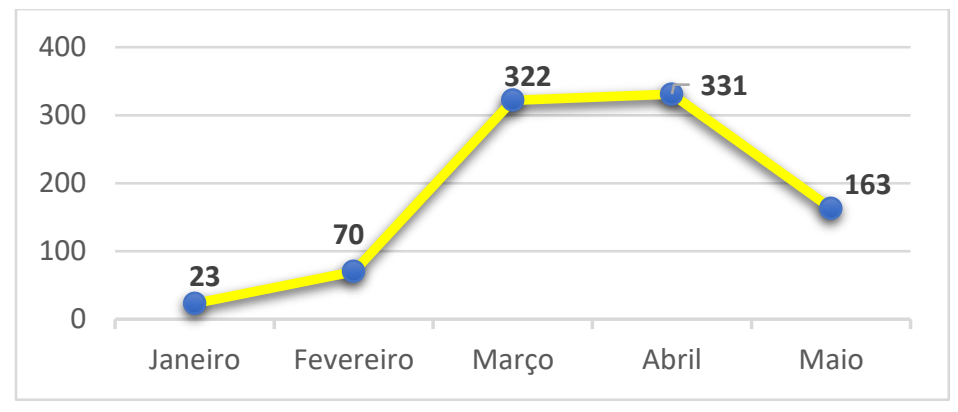

Fonte: Elaboração própria (2020).

Identificamos que é a partir do dia 13 de março que a curva desponta para a cobertura jornalística com mais de $50 \%$ do telejornal dedicado a cobrir a temática da Covid-19. Assim, no período correspondente entre 18 de março a 13 abril têm-se alguns picos no número de reportagens, totalizando 386 reportagens dedicadas à Covid-19. O pico diário máximo é identificado na seguinte ordem: 13 de abril (24), 19 de março (23), 24 e 28 de março (22), 18 de março e 11 de abril (21) e o dia $1^{\circ}$ e 9 de abril (20).

É importante ressaltar que a partir do dia 24 de abril, observamos um decréscimo da quantidade de reportagens sobre a Covid-19, mas se comparado com o início da cobertura no mês de janeiro ainda é um volume superior com média de 8 a 12 reportagens. Ainda que a curva comece a demonstrar uma queda no mês de maio, é preciso considerar que a coleta dos dados ocorreu apenas até o dia 15 , ou seja, metade do mês de maio. Observamos, também, que entre os meses de abril e maio o número de 
reportagens decaiu pela metade, aproximadamente (de 331 para 163). Assim, esse número pode ser superior ou representar uma diminuição da monotematização na cobertura jornalística do JN.

Neste sentido, entende-se que a cobertura do JN aponta, de fato, para uma monotematização da cobertura noticiosa sobre a Covid-19, no período de janeiro a maio de 2020. E conforme a doença se alastrava pelo mundo, e principalmente chegava ao Brasil, era ainda mais intensificada a cobertura do novo coronavírus. Assim, as demais pautas, momentaneamente, foram excluídas do escopo do telejornal, dando espaço para uma cobertura jornalística de saúde. Nessa vertente, também objetivamos analisar os impactos de tal monotematização na audiência do telejornal. Optamos por apresentar os dados da audiência do telejornal, por semana, a partir dos números disponibilizados pela Kantar Ibope Media. É importante destacar que, para cada um ponto de audiência, é considerado 70.559 mil domicílios sintonizados no programa; ou fazendo-se a contagem individual, cada um ponto de audiência equivale a 199.309 pessoas sintonizadas. Os dados estão apresentados na Tabela 2, a seguir:

Tabela 2 - Audiência do Jornal Nacional entre janeiro e maio de 2020

\begin{tabular}{|c|c|}
\hline Período & Audiência \\
\hline $13 / 01$ a $19 / 01$ & 29,1 \\
\hline $20 / 01$ a $26 / 01$ & 30,1 \\
\hline $27 / 01$ a $02 / 02$ & 28,4 \\
\hline $03 / 02$ a 09/02 & 28,2 \\
\hline $10 / 02$ a $16 / 02$ & 29,8 \\
\hline $17 / 02$ a $23 / 02$ & 28,3 \\
\hline $24 / 02$ a $01 / 03$ & 28,5 \\
\hline $02 / 03$ a $09 / 03$ & 29,0 \\
\hline $10 / 03$ a $15 / 03$ & 29,3 \\
\hline
\end{tabular}

João Pessoa - Brasil | ANO 8 VOL.8 N.1 | JAN./JUN. 2021 | p. 172 a 191 Revista Latino-americana de Jornalismo | ISSN 2359-375X Programa de Pós-Graduação em Jornalismo - UFPB

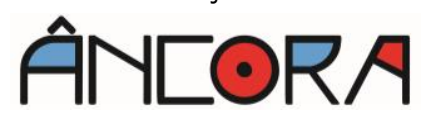




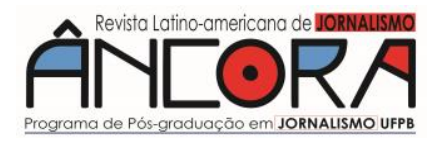

Paulo CAJAZEIRA - José SOUZA - Cleide ANTONIUTTI

\begin{tabular}{|c|c|}
\hline $16 / 03$ a $22 / 03$ & 34,2 \\
\hline $23 / 03$ a $29 / 03$ & 33,1 \\
\hline $30 / 03$ a $05 / 04$ & 30,3 \\
\hline $06 / 04$ a $12 / 04$ & 29,1 \\
\hline $13 / 04$ a $19 / 04$ & 29,7 \\
\hline $20 / 04$ a $26 / 04$ & 30,2 \\
\hline $27 / 04$ a 03/05 & 29,4 \\
\hline $04 / 05$ a $10 / 05$ & 29,2 \\
\hline $11 / 05$ a $17 / 05$ & 29,3 \\
\hline
\end{tabular}

Fonte: Kantar Ibope (2020)

Acerca da sua audiência, no período de 13 de janeiro a 15 de maio de 2020, percebe-se que o JN teve alguns picos de maior audiência, como observado nos seguintes períodos: de 20 a 26 de janeiro (30,1); de 16 a 22 de março $(34,2)$; de 23 a 29 de março $(33,1)$; de 30 de março a 5 de abril $(30,3)$ e de 20 a 26 de abril $(30,2)$. E nos outros períodos se manteve com média entre 28 e 29 pontos de audiência. 0 aumento da audiência da primeira semana (20 a 26 de janeiro) está associado às primeiras reportagens sobre o coronavírus na China, representando um total de 13 reportagens. No segundo período analisado (16 a 22 de março), a Organização Mundial da Saúde (OMS) já havia classificado o novo coronavírus como pandemia, em 11 de março, e já era possível visualizar no Brasil mais de 1000 casos do novo coronavírus.

No período de 23 a 29 de março, o noticiário do JN apresentou dados sobre o aumento de casos da Covid-19, representando mais de 4.500 casos de pessoas com o vírus e mais de 150 mortes no Brasil. Ou seja, com a situação cada vez mais alarmante e a cobertura jornalística sendo intensificada, podese atribuir o aumento da audiência ao interesse do público em se atualizar sobre os dados e compreender as medidas que estavam sendo feitas pelo governo. Posteriormente, outro pico de audiência foi registrado entre 30 de 
março a 5 de abril. Neste período, os dados sobre a incidência da Covid-19 no Brasil já revelavam mais de 500 mortes, ou seja, quase $40 \%$ a mais e mais de 12 mil infectados, cerca de $30 \%$ a mais do que no período anterior.

Por fim, o último pico de audiência do JN é identificado no período de 20 a 26 de abril de 2020. Neste período, já não é possível relacionar a audiência do telejornal apenas para a cobertura da Covid-19, mas no compartilhamento dessa audiência com as crises pelas quais o governo brasileiro estava enfrentando, podendo ser aqui elencadas em três momentos. No dia $\mathbf{1 6}$ de abril (10 reportagens) foi anunciada a demissão do então Ministro da Saúde Luiz Henrique Mandetta; no dia 24 de abril (11 reportagens), a saída do Ministro da Justiça Sérgio Moro e no dia 15 de maio (7 reportagens) a saída do segundo Ministro da Saúde, Nelson Teich, que ficou cerca de um mês no cargo. Assim, tais crises, em conjunto com o aumento de casos de infectados (mais de $218 \mathrm{mil}$ ) e de mortes (mais de $14 \mathrm{mil}$ ), representaram o crescimento da audiência do JN.

Para melhor visualizar as interferências das crises políticas na cobertura jornalística da Covid-19, os dados serão representados graficamente. Do total de reportagens coletadas (909), os meses de abril e maio juntos representam $71 \%$ de notícias dedicadas à cobertura Covid-19.

Gráfico 2 - Porcentagem de reportagens sobre a Covid-19 no Jornal Nacional

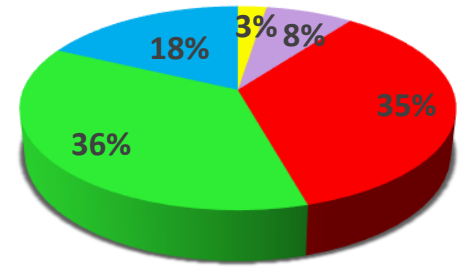

Janeiro Fevereiro Março abril Maio

Fonte: Elaboração própria (2020)

Diante da porcentagem de reportagens nos meses de abril e maio de 2020 , observamos que $65 \%$ delas estão relacionadas com as crises do governo

João Pessoa - Brasil | ANO 8 VOL.8 N.1 | JAN./JUN. 2021 | p. 172 a 191 Revista Latino-americana de Jornalismo | ISSN 2359-375X Programa de Pós-Graduação em Jornalismo - UFPB 


\section{ÂNCORA}

\section{Paulo CAJAZEIRA - José SOUZA - Cleide ANTONIUTTI}

produzidas durante o mês de abril, e 35\% durante o mês de maio. Assim, durante o mês de abril a monotematização da cobertura jornalística da Covid19 foi diminuída para que o JN pudesse noticiar as crises a partir das saídas dos Ministérios da Saúde e da Justiça. Como no mês de maio, considerando que a coleta de dados contemplou apenas metade do mês (até o dia 15), as notícias sobre as crises governamentais, especialmente sobre a saída do segundo ministro da Saúde, Nelson Teich, teve menos impacto do que as duas anteriores.

Gráfico 3 - Reportagens de abril a maio sobre a Covid-19 no Jornal Nacional

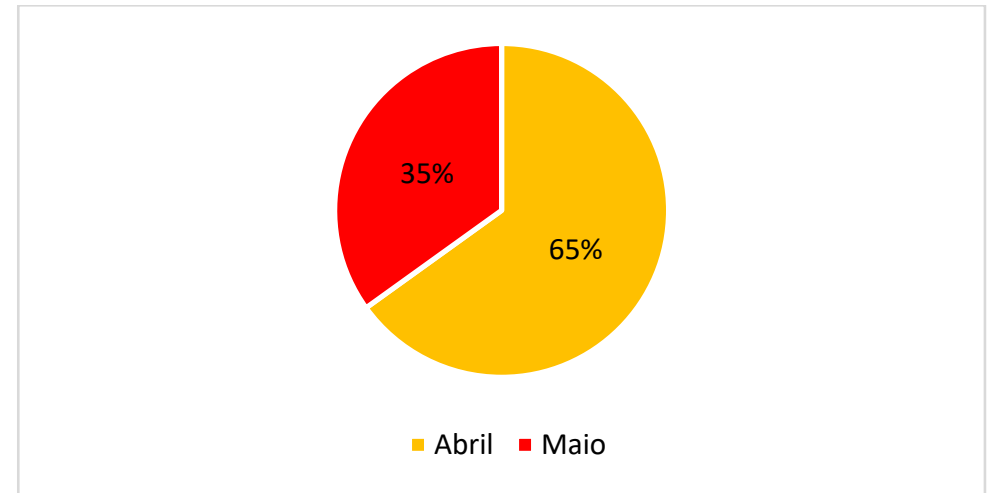

Fonte: Elaboração própria (2020)

Desse modo, podemos aferir que a monotematização da cobertura jornalística de saúde, a partir da Covid-19, é redimensionada apenas quando o Jornal Nacional noticia as crises provocadas pelo governo, como a saída dos ministros descritas anteriormente. Assim, nos dias 16 e 24 de abril e no dia 15 de maio, a cobertura jornalística do JN foi dedicada, majoritariamente, sobre a saída dos ministros. Apontamos também que as saídas dos dois ministros da saúde mantinham, de certa forma, relação com essa cobertura de saúde, mas o destaque principal deu-se sobre as relações, conflitos entre o Governo Federal e os ministros, e não sobre as ações que esses atores estavam desempenhando para melhorar a saúde pública no Brasil. 


\section{Considerações finais}

O estudo empreendido neste artigo aponta, frente ao dimensionamento, o avanço de casos e espalhamento do novo coronavírus desde a China até a sua chegada no Brasil. A cobertura jornalística do Jornal Nacional foi se tornando monotemática a partir da preocupação de organizações como a OMS e o desconhecimento sobre os efeitos do vírus, as formas de contágios e as orientações sanitárias com seus devidos cuidados. Assim, desde o mês de janeiro, o JN noticiou alguns informes sobre o surgimento do novo coronavírus, mas sem grandes alardes por ser um caso ainda restrito na cidade chinesa de Wuhan.

Contudo, no mês de fevereiro os casos foram se agravando, e um número expressivo de casos de mortes foram sendo registrados e noticiados pelo jornalismo internacional. No dia 11 de março de 2020, a OMS decreta a pandemia, e com isso também verificamos que há uma maior concentração da cobertura jornalística sobre a Covid-19 neste mês, aqui no Brasil, e, especificamente, no telejornal utilizado como objeto de estudo.

Mesmo não sendo um fenômeno novo, a monotematização dessa cobertura, durante os primeiros meses de 2020, mostrou-se expressiva. 0 pico apresenta-se durante o mês de março, com 322 reportagens e também em abril com 331 reportagens sobre a Covid-19.

Porém, uma vez que a observação levantada inicialmente, de que havia o direcionamento de cobertura monotemática, esta foi realmente identificada e demonstrada, sobretudo nos meses de março e abril. As únicas interferências em reportagens que versavam sobre a temática da Covid-19 foram visualizadas durante as crises provocadas pelo governo, que de certa forma também estavam relacionadas com a temática da cobertura, a exemplo das saídas dos dois ministros da Saúde.

Apenas a saída do Sérgio Moro pode ser compreendida como um eixo mais distante dessa cobertura monotemática. Conclui-se, que a 


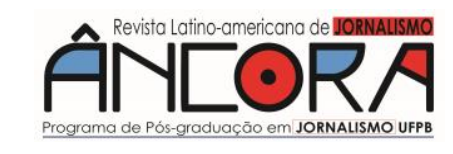

Paulo CAJAZEIRA - José SOUZA - Cleide ANTONIUTTI

monotematização identificada na cobertura jornalística do JN implicou em picos de audiência, bem como no direcionamento do telejornal para noticiar, narrar e explicitar as ocorrências, os fatos e as transformações do novo coronavírus.

\section{Referências}

BARDIN, Laurence. Análise de conteúdo. Tradução de Luís Antero Reto e Augusto Pinheiro. São Paulo: Edições 70, 2016.

CORREIA, João Carlos. 0 admirável mundo das notícias: teorias e métodos. Covilhã: LabCom Books, 2011, pp. 81-92

DEARING, James W., ROGERS, Everett. Agenda setting. Thousand Oaks, CA.: Sage, 1996.

ERBOLATO, Mário. Técnicas de codificação em Jornalismo. São Paulo: Ática, 2006.

KANTAR IBOPE MEDIA. Audiência do Jornal Nacional. 2020. Disponível em: https://www.kantaribopemedia.com/. Acesso em: 6 set. 2020.

GLOBOPLAY. Jornal Nacional. [s/d]. Disponível em:

$<$ https://globoplay.globo.com/jornal-nacional/t/MyCrVrr6gW/>. Acesso em: 6 set. 2020.

MEMÓRIA GLOBO. Jornal Nacional. [s/d]. Disponível em:

$<$ https://memoriaglobo.globo.com/jornalismo/jornalismo-e-telejornais/jornalnacional/>. Acesso em: 6 set. 2020.

MINAYO, Maria Cecília S.; SANCHES, Odécio. Quantitativo-qualitativo: oposição ou complementaridade? Cadernos de Saúde Pública, Rio de Janeiro, v. 9, n. 3, p. 239-262, jul./set., 1993.

McCOMBS Maxwell. Estableciendo la agenda. El impacto de los médios en la opinión pública y en el conocimiento. Barcelona: Ediciones Paidós, 2006. McCOMBS, Maxwell. A Look at Agenda-setting: past, present and future.

Journalism Studies, Austin, v. 6, n. 4, p. 543-557, 2005.

McCOMBS, Maxwell; LOPEZ-ESCOBAR, Esteban; LLAMAS, Juan Pablo. Setting the agenda of attributes in the 1996 Spanish general election. Journal of Communication, Oxford, v. 50, n. 2, p. 77-92, 2000.

McCOMBS, Maxwell ; SHAW, Donald. The agenda-setting function of mass media. The Public Opinion Quarterly, Oxford, v. 36, n. 2, p. 176-187, 1972.

PENA, Felipe. Teoria do Jornalismo. São Paulo: Contexto, 2010.

RICHARDSON, Roberto Jarry. Pesquisa social: métodos e técnicas. 3. ed. São Paulo: Atlas, 2011.

SANTOS, Boaventura S. El corononavirus y nuestra contemporaneidade. In: KASSIR et al. Alerta global: políticas, movimentos sociales y futuros en disputa en tiempos de pandemia. Buenos Aires: CLACSO; Lima: ALAS, 2020, p. $35-40$. 
TRAQUINA, Nelson. Teorias do jornalismo: porque as notícias são como são. Florianópolis: Insular, 2004.

TRAQUINA, Nelson. $\mathbf{O}$ estudo do jornalismo no século XX. 1. reimp. São Leopoldo, RS: Unisinos, 2002.

TUCHMAN, Gaye. Making News: a study in the construction of reality. New York: The Free Press, 1978.

WARD, Mike. Jornalismo online. São Paulo: Roca, 2006.

WHITE, D M. "The 'Gatekeeper': A Case Study in the Selection of News". Journalism Quaterly, vol. 27, n. 4, p.382-39, 1950

WOLF, Mauro. Teorias das comunicações de massa. 2. ed. São Paulo: Martins Fontes, 2005.

WOLTON, Dominique. Elogio do grande público: uma teoria crítica da televisão. São Paulo: Editora Ática, 1996. 